\title{
Implementation Workshop Curriculum 2013 In Learning In The District of Babar Islands - Southwestern Maluccas Regions
}

\author{
Mieke Souisa ${ }^{1}$, Jacob Anaktototy², Wilhelmina Unmehopa ${ }^{3}$, Mariana Hukubun', Emma \\ Rumahlewang ${ }^{5}$, Jonas Solissa ${ }^{6}$, Johana Matitaputty ${ }^{7}$ \\ 1, 2, 3, 4, 5, 6, 7Pattimura University Ambon \\ Email: 1ms.souisa1512@gmail.com, 2jopi.anaktototy18@gmail.com, 3wunmehopa5@gmail.com, \\ 4marianahukubun01@gmail.com, 5emmarumahlewang02@gmail.com,6jonassolisa@gmail.com, \\ 7jokematitaputty0@gmail.com \\ d \\ https://doi.org/10.36526/gandrung.v1i2.932
}

\begin{abstract}
The 2013 curriculum has been approved and implemented in the Indonesian learning system, since a few years ago, to have undergone a number of improvements. Based on some studies in the cities of Ambon and Maluku particularly in the physical and exercise programs, indicates that a teacher's lack of ability to plan the learning process using the 2013 curriculum, both at an elementary level, middle school, and high school. Much of what follows, two are unfamiliar with the 2013 curriculum procedure in learning because it rarely participates in any related training. Subsequent methods used by teams for established purposes were achieved: (a) problem identification, (b) social approach, (c) discourse, (d) discussion, (e) evaluation, (f) drawing conclusions. Results based on the procedural process developed by understanding participants' concepts of curriculum 2013 implementation procedures, in both cases; (a) plan learning, (b) procedures in selecting and using and applying active learning models in saintifical, authentic and also thematic approaches in classroom learning, (c) the evaluation process in classroom learning, in order to create interactive students.
\end{abstract}

Keyword: Workshop, Implementation, Curriculum of 2013, Learnig

\section{Pendahuluan}

Tri Dharma Perguruan Tinggi merupakan tiga hal pokok yang wajib dilaksanakan dan dikembangkan secara berkesinaambungan diseluruh unsur sivitas akademika, diantaranya dosen dan juga mahasiswa. Tri dharma inipun bukan hanya sebuah slogan saja, namun haruslah menjadi budaya yang harus disadari dan terinternalisasi bagi seluruh civitas akademika, sehingga cita-cita sebenarnya dari sebuah tri dharma perguruan tinggi dapat terwujud dan terimplementasikan dengan baik.

Pengabdian masyarakat merupakan unsur ketiga setelah unsur pertama; pendidikan, serta unsur kedua; penelitian dan pengembangan dari Tri Dharma Perguruan Tinggi, dan sepenuhnya dilaksanakan oleh seluruh civitas akademika sesuai bidang kompetensi pada masing-masing program studi.

Pendidikan Jasmani Kesehatan dan Rekreasi (Penjaskesrek) merupakan salah satu program studi dibawah naungan jurusun IImu Pendidikan, Fakultas Keguruan dan IImu Pendidikan Universitas

Volume 1, Number 2, Juli 2020| 25 Implementation Workshop Curriculum 2013 In Learning In The District of Babar Islands - Southwestern Maluccas Regions

Mieke Souisa, Jacob Anaktototy, Wilhelmina Unmehopa, Mariana Hukubun, Emma Rumahlewang, Jonas Solissa, Johana Matitaputty 
GANDRUNG: Jurnal Pengabdian Kepada Masyarakat ISSN: 2721-6136 (Online)

Pattimura, dimana setiap unsur didalamnya termasuk mahasiswa himpunan program studi wajib melaksanakan kegiatan pengabdian masyarakat. Terjun dan berinteraksi secara langsung ke masyarakat merupakan salah satu hal strategis dalam mengembangkan kegiatan yang diharapkan dapat berdampak positif bagi masyarakat.

Berdasarkan aura dari pengabdian kepada masyarakat inilah, maka prodi penjaskesrek melaksanakan kegiatan bagi masyarakat yang sesuai dengan kompetensi prodi dalam bidang pembelajaran, dimana kegiatan tersebut merupakan ansi kegiatan dosen program studi berupa "Workshop Implementasi Kurikulum 2013 dalam Pembelajaran di Kecamatan Pulau-Pulau Babar, Kabupaten Maluku Barat Daya." Kegiatan ini sendiri berlangsung pada 11 dan 12 Juni 2019, bertempat Gedung serbaguna Kecamatan di kecamatan Pulau-pulau Babar Kabupaten Maluku Barat Daya. Meskipun pelaksanaannya masih dalam suasana libur semester, namun para peserta yang menghadiri kegiatan ini berjumlah 104 (seratus empat) orang, yang notabene adalah para guru yang berasal dari kecamatan PP. Babar, bahkan adapula yang berasal dari kecamatan disekitar, yaitu kecamatan Babar Timur, dan Kecamatan pulau Wetang.

Workshop berupa implementasi kurikulum 2013 yang disajikan bagi para guru di pulau-pulau babar dan sekitarnya ini dilatarbelakangi oleh fakta empiris yang ditemui selama ini bahwa umumnya para guru di kabupaten/kota yang dekat dengan pusat dinas pendidikan sendiri saja belum maksimal dalam menerapkan kurikulum 2013 dalam pembelajaran sesuai dengan prosesdur dalam kurikulum 2013 yang sudah beberapa tahun sah dijalankan di Indonesia. Tidak menutup kemungkinan di kecamatan terluar kabupaten Maluku Barat Daya pun mengalamai hal yang sama bahkan pula miris dari kondisi yang terlihat, karena minimnya jangkauan LPTK bahkan Instansi terkait yang bertanggung jawab untuk mengembangkan keprofesian guru dilapangan. Bahkan selama ini pun dunia pendidikan di kabupaten Maluku Barat Daya khususnya kecamatan Pulau-Pulau Babar jarang tersentuh oleh kegiatan-kegiatan dari dinas atau lembaga terkait, guna peningkatan professional di pulau terluar ini.

Oleh karenanya program studi pendidikan jasmani kesehatan dan rekreasi, melalui tim pengabdian kepada masyarakat yaitu dosen program studi, melaksanakan kegiatan pengabdian kepada masyarakat yaitu "Workshop Implementasi kurikulum 2013 dalam pembelajaran" yang berpusat di kecamatan Pulau-Pulau Babar Kabupaten Maluku Barat Daya.

\section{Metode}

Sebagaimana kita ketahui bersama bahwa kegiatan pengabdian yang dilaksanakan secara 
GANDRUNG: Jurnal Pengabdian Kepada Masyarakat ISSN: 2721-6136 (Online)

mandiri maupun secara institusi, harus mempunyai tahapan pelaksanaan, sehingga dalam kegiatan Workshop Implementasi Kurikulum 2013 di Kecamatan Pulau-Pulau Babar Kabupaten Maluku Barat Daya, dilalui dengan tahapan sebagai berikut: (a) Identifikasi Masalah, (b) pendekatan social, (c) ceramah, (d) diskusi, (e) evaluasi, (f) menarik kesimpulan.

Selanjutnya masing-masing tahapan atau metode dalam kegiatan ini dapat dijelaskan sebagai berikut:

1. Identifikasi Masalah

Sebagaimana telah dipaparkan dalam bagian pendahuluan, dimana fakta empiris yang ditemui dilapangan berdasarkan beberapa hasil penelitian pada tahun 2018, yang dilengkapi dengan beberapa penelitian lanjutan berupa penelitian kolaborasi yang mengungkapkan kemampuan guru penjasor dalam menerapkan kurikulum 2013, maka berdasarkan hasil-hasil penelitian tersebut, ditemui kemampuan guru penjasor pada beberapa sekolah negeri di kota Ambon dan juga di kabupaten Maluku Tengah menerapkan kurikulum 2013 dalam pembelajaran sangat rendah. Sehingga berdasarkan hasil penelitian dan pendalaman hasil terhadap para subyek dalam penelitian, pada umumnya diperhadapkan dengan permasalahan utama yaitu "kurang memahami dengan baik bagaimana menerapkan kurikulum 2013 dalam pembelajaran penjaor.

Jika kota Ambon yang merupakan barometer pendidikan di provinsi Maluku kenyataan bias seperti demikian, maka bagaimanakah dengan guru penjasor dikabupaten dan kecamatan pulau terluar, maka berdasarkan hasil-hasil penelitian tersebut, kami pun lalu mencoba untuk melakukan wawancara kepada guru penjasor di kecamatan Pulau-Pulau Babar Kabupaten Maluku Barat Daya.

Hasil wawancara ini, tidaklah jauh berbeda dengan kenyataan yang ditemui dikota Ambon dan Maluku Tengah. Maka program studi menetapkan untuk melakukan kegiatan untuk meningkatkan pemahaman para tenaga pendidik di Kecamatan Pulau-Pulau Babar Kabupaten Maluku Barat Daya yang merupakan salah satu diantara beberapa kecamatan terluar di Provinsi ini sebagai lokasi pelaksanaan kegiatan pengabdian kepada masyarakat dimaksud.

2. Pendekatan Sosial

Setelah tim pengabdian yang ditunjuk berdasarkan keputusan rapat kerja Program Studi melakukan koordinasi dengan pimpinan Fakultas, guna mendapatkan persetujuan melaksanakan pengabdian kepada masyarakat dimaksud. Sebagaimana yang tertuang dalam Surat Tugas Dekan Fakultas Keguruan dan IImu Pendidikan Universitas Pattimura Ambon, Nomor: 99/UN13.1.3/KP/2020, Tanggal 13 Januari 2020, maka kamipun melakukan berbagai bentuk 
pendekatan, guna tercapainya tujuan kegiatan dimaksud antaralain;

a. Sosialisasi kepada para pelaku olahraga dalam hal ini para guru pendidikan jasmani, dilaksanakan pada Sabtu, 13 April 2019 bertempat di aula SMP Kristen Pulau-Pulau Babar. Kegiatan sosialisasi ini dilaksanakan dengan tujuan untuk menyampaikan maksud dan tujuan kegiatan pengabdian kepada masyarakat yang akan dilaksanakan oleh program studi, berupa "workshop implementasi kurikulum 2013 dalam pembelajaran", yang ditujukan untuk para guru jenjang sekolah dasar (SD), jenjang sekolah menengah pertama (SMP), dan jenjang sekolah menengah atas (SMA), di kecamatan Pulau-Pulau Babar dan sekitarnya.

b. Seiring dengan pengiriman surat pemberitahuan dari dekan Fakultas Keguruan dan IImu Pendidikan, nomor: 2603/UN13.1.3/KP/2019, dan nomor: 2604/UN13.1.3/KP/2019 tentang "penyampaian kegiatan pengabdian", yang ditujukan ke koordinator pendidikan kecamatan PulauPulau Babar, dan Babar Timur serta pemerintah kecamatan Pulau-Pulau Babar, maka segala bentuk persiapan baik dilokasi maupun di homebase untuk memnyiapkan segala keperluan pun dilaksanakan.

Selanjutnya, berdasarkan hasil yang dilakukan pada tahapan koordinasi maka berdasarkan Surat Tugas dari Dekan Fakultas Keguruan dan IImu Pendidikan Universitas Pattimura, nomor: 3172/UN13.1.3.1/KP/2019, dalam rangka pelaksanaan kegiatan pengabdian masyarakat dosen program studi penjaskesrek FKIP Unpatti di Maluku Barat Daya, Khususnya di desa Tepa, Kecamatan Pulau-pulau Babar, kamipun melaksanakan kegiatan Pengabdian Kepada Masyarakat pada tanggal 06 Juni 2019.

3. Ceramah

Kegiatan ceramah dilakukan untuk menyampaikan isi materi dalam kegiatan workshop dimaksud. Dalam isi ceramah dimaksud, materi yang disampaikan kepada para tenaga pendidik di kecamatan ini antaralain;

a. Merencanakan Pembelajaran dengan kurikulum 2013, yang disampaikan oleh M. Souisa, S.Pd., M.Pd.

b. Model Pembelajaran Aktif / Saintifik, yang disampaikan oleh Prof. Dr. J. Anaktototy, M.Pd.

c. Evaluasi Pembelajaran dengan Kurikulum 2013, yang disajikan oleh Dra. W. unmehopa MS.

4. Diskusi

Tahap diskusi merupakan proses umpan balik yang dilakukan oleh pemateri dengan para peserta workshop secara bervariasi, yang bertujuan untuk; 
a. Menggali berbagai permasalahan mendalam yang terjadi dilapangan, terkait implementasi kurikulum 2013 yang dilakukan oleh para guru dalam proses pembelajaran, permasalahan apa yang dihadapi, dan factor-faktor yang menghambat dalam pembelajaran dengan kuyrikulum 2013.

b. Setelah itu materi akan disajikan untuk membuka pemahaman dan menanamkan konsep penerapan kurikulum; yang dimulai dengan bagaimana merencanakan pembelajaran dengan kurikulum 2013, bagaimana procedure menerapkan pendekatan saintifik dalam pembelajaran, dan juga bagaimana melakukan evaluasi dalam pembelajaran dengan menggunakan kurikulum 2013.

5. Evaluasi

Evaluasi merupakan cara kami untuk mengukur daya serap guru terhadap materi yang disajikan, maupun berbagai diskusi yang disajikan dalam kegiatan workshop dimaksud. Tahapan evaluasi inipun dilakukan dengan cara para guru memasukan hasil kerja (tugas yang diberikan oleh pemateri dalam kaitannya dengan (a) merencakan pembelajaran, (b) menerapkan pendekatan saintifik, dan bagaimana melakukan evaluasi dalam pembelajaran yang sesuai cirikhas matapelajaran dan jenjang serta tingkatan sekolah. Selain itu berbagai komunikasi diskusi pun dibangun antara guru dan pemateri selama kami berada di lokasi kegiatan.

6. Menarik Kesimpulan

Paparan secara ringkas yang merupakan hasil dari kegiatan workshop implementasi kurikulum 2013 dalam pembelajaran yang dilaksankan di desa Tepa Kecamatan Pulau-Pulau Babar Kabupaten Maluku Barat Daya yaitu "berkembangnya pemahaman konsep peserta tentang prosedur implementasi kurikulum 2013, baik dalam hal; (a) merencanakan pembelajaran, (b) prosedur dalam memilih dan menggunakan dan menerapkan model pembelajaran yang aktif dalam pendekatan saintifik, autentik dan juga tematik dalam pembelajaran dikelas, (c) proses evaluasi dalam pembelajaran dikelas, agar dapat menghasilkan siswa yang aktif interaktif."

\section{Hasil dan Diskusi}

Adapun tenaga pendidik yang ikut serta dalam kegiatan workshop impementasi kurikulum 2013 dalam pembelajaran keseluruhan berjumlah 104 orang, berasal dari 3 kecamatan yaitu; kecamata berasal dari 3 kecamatan Pulau-Pulau Babar, serta kecamatan sekitar yang mengetahui pelaksanaan kegiatan ini, yaitu kecamatan Babar Timur, Kecamatan Pulau Wetang.

Berdasarkan dialog yang dilaksanakan diawal penyajian materi, ternyata dilema implementasi kurikulum dalam pembelajaran dengan meggunakan kurikulum 2013 rata-rata sama, dimana tenaga 
GANDRUNG: Jurnal Pengabdian Kepada Masyarakat ISSN: 2721-6136 (Online)

pendidik kebingungan dalam merencanakan pembelajaran. Oleh karena mereka tidak pernah ikut serta dalam kegiatan yang bertujuan mensosialisasikan kurikulum 2013 dalam pembelajaran.
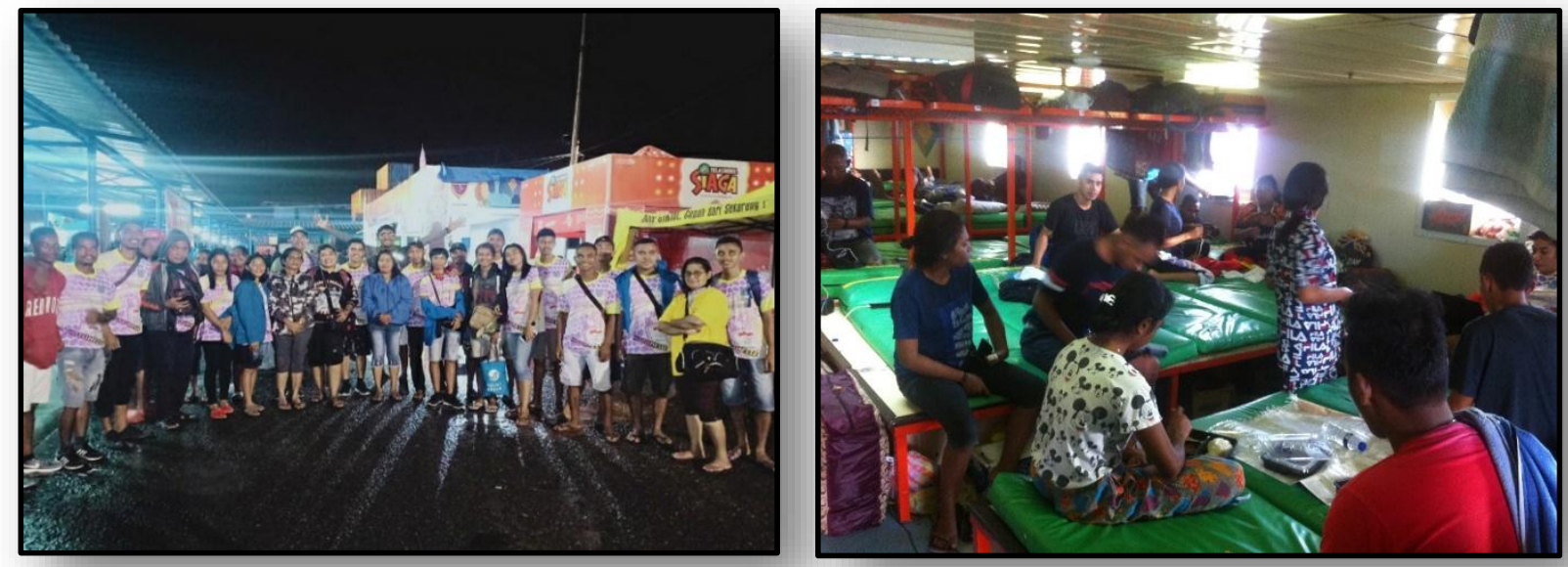

Gambar 1. Keberangkatan Tim Pengabdian menuju ke Lokasi Pengabdian Desa Tepa Kecamatan Pulau-Pulau Babar, Kabupaten Maluku Barat Daya Dengan Menggunakan KM. Pangrango.
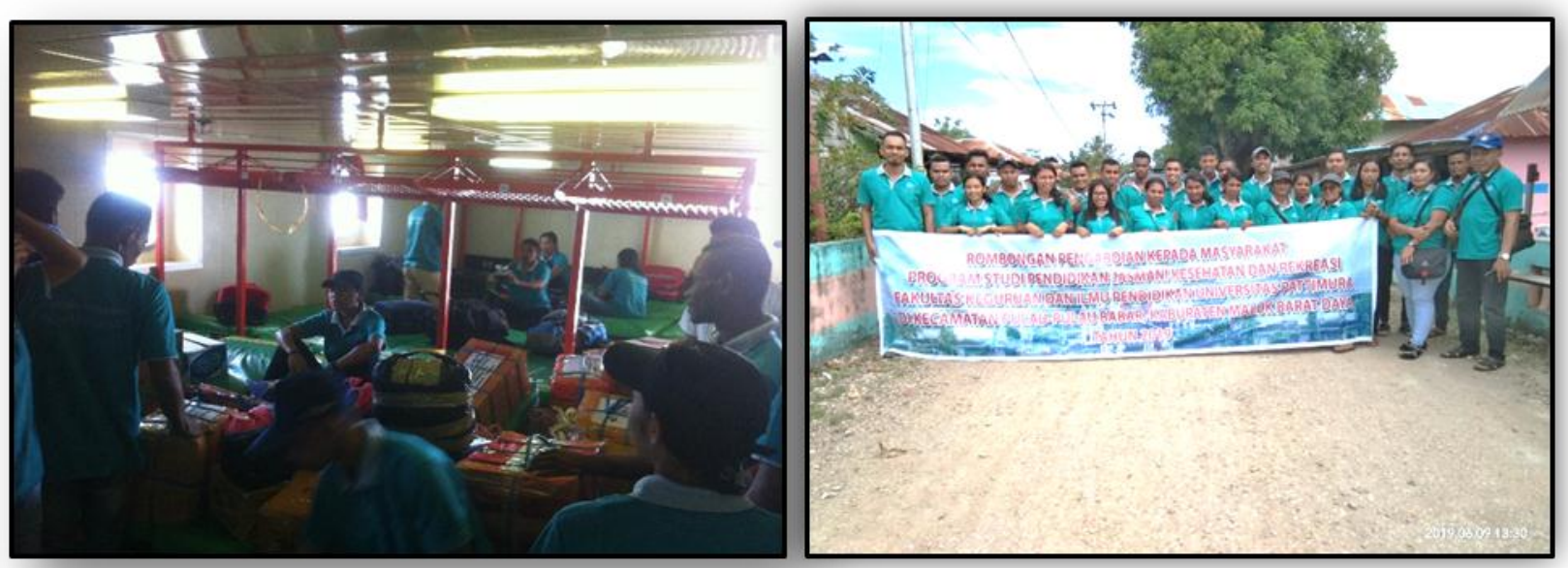

Gambar 2. Tiba di Lokasi Pengabdian Desa Tepa Kecamatan Pulau-Pulau Babar, Kabupaten Maluku Barat Daya Dengan Menggunakan KM. Pangrango.

Sehingga ketika materi disajikan oleh pemateri, para peserta sangat antusias dalam memperhatikan maupun bertanya maupun berdiskusi denga pemateri. Sehingga waktu yang disediakan sepertinya tidaklah cukup waktu yang disediakan untuk berdiskusi. Sehingga disela-sela waktu beristirahat pun mereka selalu menggunaka moment tersebut. Adapun materi yang disajikka antara lain: 1. Merencanakan pembelajaran dengan kurikulum 2013.

2. Memilih pendekatan dan metode yang aktif dan interaktif, yang sesuai denga tuntutan kurikulum 2013 .

Volume 1, Number 2, Juli 2020| 30 Implementation Workshop Curriculum 2013 In Learning In The District of Babar Islands - Southwestern Maluccas Regions

Mieke Souisa, Jacob Anaktototy, Wilhelmina Unmehopa, Mariana Hukubun, Emma Rumahlewang, Jonas Solissa, Johana Matitaputty 
GANDRUNG: Jurnal Pengabdian Kepada Masyarakat ISSN: 2721-6136 (Online)

3. Implementasi pendekata ataupun metode yang sesuai dan telah direncanakan sebelumnya, dalam pembelajaran denga kurikulum 2013.

4. Merencanakan evaluasi dalam pembelajaran dengan kurikulum 2013.

5. Implementasi evaluasi yang telah direncanakan sebelumnya.

Sehingga secara rinci rangkaian kegiatan workshop implementasi kurikulum 2013 dalam pembelajaran dapat dilihat dalam tabel 2 (dua) dibawah ini.

Tabel 1 Susunan Acara Workshop Implementasi Kurikulum 2013 dalam Pembelajaran Bagi Tenaga Pendidik di Kecamatan PP. Babar Kabupaten Maluku Barat Daya.

HARI/TGL. WAKTU

MATERI

PENANGG. JAWAB

\begin{tabular}{|c|c|c|c|c|}
\hline \multirow{8}{*}{ 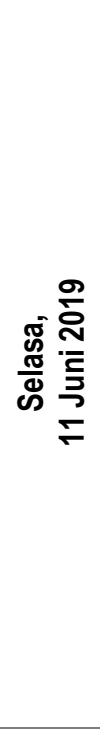 } & $\begin{array}{l}08.00 \text { wit. s.d } 08.45 \\
\text { wit. }\end{array}$ & 1. & Registrasi Peserta. & Panitia \\
\hline & $\begin{array}{l}09.00 \text { wit. s.d } 09.30 \\
\text { wit. }\end{array}$ & 2. & Pembukaan. & Panitia \\
\hline & $\begin{array}{l}09.30 \text { wit. s.d } 10.00 \\
\text { wit. }\end{array}$ & 3. & Coffee Morning. & Panitia \\
\hline & $\begin{array}{c}10.00 \text { wit. s.d } 13.00 \\
\text { wit. }\end{array}$ & 4. & $\begin{array}{l}\text { Merencanakan Pembelajaran } \\
\text { dengan kurikulum } 2013\end{array}$ & $\begin{array}{l}\text { M. Souisa, S.Pd., M.Pd. } \\
\text { Viktor H. R. Apituley, S.Pd., } \\
\text { M.Pd. }\end{array}$ \\
\hline & $\begin{array}{l}13.00 \text { wit. s.d } 14.00 \\
\text { wit. }\end{array}$ & 5. & Lunch. & Panitia \\
\hline & $\begin{array}{l}14.00 \text { wit. s.d } 15.30 \\
\text { wit. }\end{array}$ & 6. & 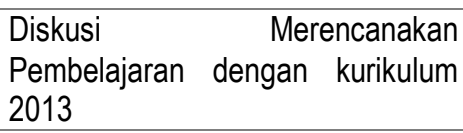 & $\begin{array}{l}\text { M. Souisa, S.Pd., M.Pd. } \\
\text { Viktor H. R. Apituley, S.Pd., } \\
\text { M.Pd. }\end{array}$ \\
\hline & $\begin{array}{l}15.30 \text { wit. s.d } 16.00 \\
\text { wit. }\end{array}$ & 7. & Breakfast. & Panitia \\
\hline & 16.00 wit. s.d selesai & 8. & $\begin{array}{l}\text { Implementasi } \quad \text { Pembelajaran } \\
\text { dengan Kurikulum } 2013 .\end{array}$ & $\begin{array}{l}\text { Prof. Dr. J. Aaktototy, M.Pd. } \\
\text { M. Souisa, S.Pd., M.Pd. }\end{array}$ \\
\hline \multirow{8}{*}{ 宽 } & $\begin{array}{l}07.30 \text { wit. s.d } 09.30 \\
\text { wit. }\end{array}$ & 1. & Model Pembelajaran Aktif / Saintifik. & $\begin{array}{l}\text { Prof. Dr. J. Anaktototy, M.Pd. } \\
\text { M. Souisa. S.Pd., M.Pd }\end{array}$ \\
\hline & $\begin{array}{l}09.30 \text { wit. s.d } 10.00 \\
\text { wit. }\end{array}$ & 2. & Coffee Morning. & Panitia \\
\hline & $\begin{array}{l}10.00 \text { wit. s.d } 12.00 \\
\text { wit. }\end{array}$ & 3. & 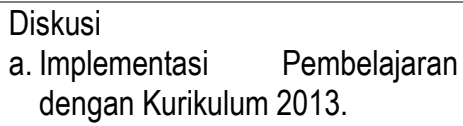 & $\begin{array}{l}\text { Prof. Dr. J. Anaktototy, M.Pd. } \\
\text { M. Souisa. S.Pd., M.Pd } \\
\text { M. E. Lataheru, S.Pd., M.Pd. }\end{array}$ \\
\hline & & & $\begin{array}{l}\text { b. Model Pembelajaran Aktif I } \\
\text { Saintifik. }\end{array}$ & \\
\hline & $\begin{array}{l}12.00 \text { wit. s.d } 12.45 \\
\text { wit. }\end{array}$ & 4. & Lunch. & Panitia \\
\hline & $\begin{array}{c}12.45 \text { wit. s.d } 14.00 \\
\text { wit. }\end{array}$ & 5. & $\begin{array}{l}\text { Rencana Evaluasi Pembelajaran } \\
\text { dengan kurikulum } 2013 .\end{array}$ & $\begin{array}{l}\text { M.D. Hukubun, S.Pd., M.Or. } \\
\text { Dr. E. Rumahlewang, M.Pd. }\end{array}$ \\
\hline & $\begin{array}{l}14.00 \text { wit. s.d } 15.30 \\
\text { wit. }\end{array}$ & 6. & $\begin{array}{lr}\text { Implementasi } & \text { Evaluasi } \\
\text { Pembelajaran dengan } & \text { kurikulum } \\
2013 . & \end{array}$ & $\begin{array}{l}\text { W. Unmehopa, MS } \\
\text { J. Matitaputty, S.Pd., M.Pd. }\end{array}$ \\
\hline & $\begin{array}{l}15.30 \text { wit. s.d } 16.60 \\
\text { wit. }\end{array}$ & 7. & Breakfast. & Panitia \\
\hline
\end{tabular}

Volume 1, Number 2, Juli 2020| 31 Implementation Workshop Curriculum 2013 In Learning In The District of Babar Islands - Southwestern Maluccas Regions

Mieke Souisa, Jacob Anaktototy, Wilhelmina Unmehopa, Mariana Hukubun, Emma Rumahlewang, Jonas Solissa, Johana Matitaputty 
GANDRUNG: Jurnal Pengabdian Kepada Masyarakat ISSN: 2721-6136 (Online)

\begin{tabular}{|c|c|c|c|c|}
\hline $\begin{array}{l}16.00 \text { wit. s.d } 17.30 \\
\text { Wit. }\end{array}$ & 8. & $\begin{array}{ll}\text { Diskusi } \\
\text { a. } & \text { Rencana } \\
& \text { Pembelajaran } \\
& \text { kurikulum } 2013 . \\
\text { b. } & \text { Implementasi } \\
& \text { Pembelajaran } \\
& \text { kurikulum } 2013 .\end{array}$ & $\begin{array}{r}\text { Evaluasi } \\
\text { dengan } \\
\text { Evaluasi } \\
\text { dengan }\end{array}$ & $\begin{array}{l}\text { M.D. Hukubun, S.Pd., M.Or } \\
\text { Dr. E. Rumahlewang, M.Pd. } \\
\text { W. Unmehopa, MS } \\
\text { J. Matitaputty, S.Pd., M.Pd. }\end{array}$ \\
\hline $\begin{array}{l}17.30 \text { wit. s.d } 18.00 \\
\text { wit. }\end{array}$ & 9. & Penutupan & & Panitia \\
\hline
\end{tabular}

Berdasarkan rangkaian kegiatan yang telah dirincikan dalam table 2 (dua) diatas, bagi ke 104 (seratus empat) peserta workshop yang berasal dari tenaga pendidik dari kecamatan Pulau-Pulau Babar maupu kecaman Babar Timur, juga dari kecamatan Pulau Wetang tanggal 11 dan 12 Juni 2019 ini dapat mengembagkan konsep dan pemahaman dari para peserta sebagai berikut;

1. Peserta menujukkan antusias mereka dalam setiap kesempatan diskusi, yang ditujukan bagi pemateri, dan umumnya bertujuan agar supaya pemateri dapat meluruskan pola pikir peserta saat merencanakan pembelajaran dengan kurikulum 2013.

2. Peserta memahami bagaimana merencanakan pembelajaran dengan kurikulum 2013.

3. Peserta memahami pendekatan yang umumnya digunakan dalam pembelajaran sesuai dengan cirikhas materi, baik pedekatan saintifik, tematik maupun metode pembelajaran yang sesuai dengan kurikulum 2013.

4. Berkembangnya pemahaman peserta tentang prosedur implementasi kurikulum 2013 dalam pembelajaran.

5. Peserta memahami bagaimana merencanakan evaluasi dalam kurikulum 2013.

6. Peserta memahami proses implementasi evaluasi yang telah direncanakan sebelumnya dengan kurikulum 2013. 
GANDRUNG: Jurnal Pengabdian Kepada Masyarakat ISSN: 2721-6136 (Online)
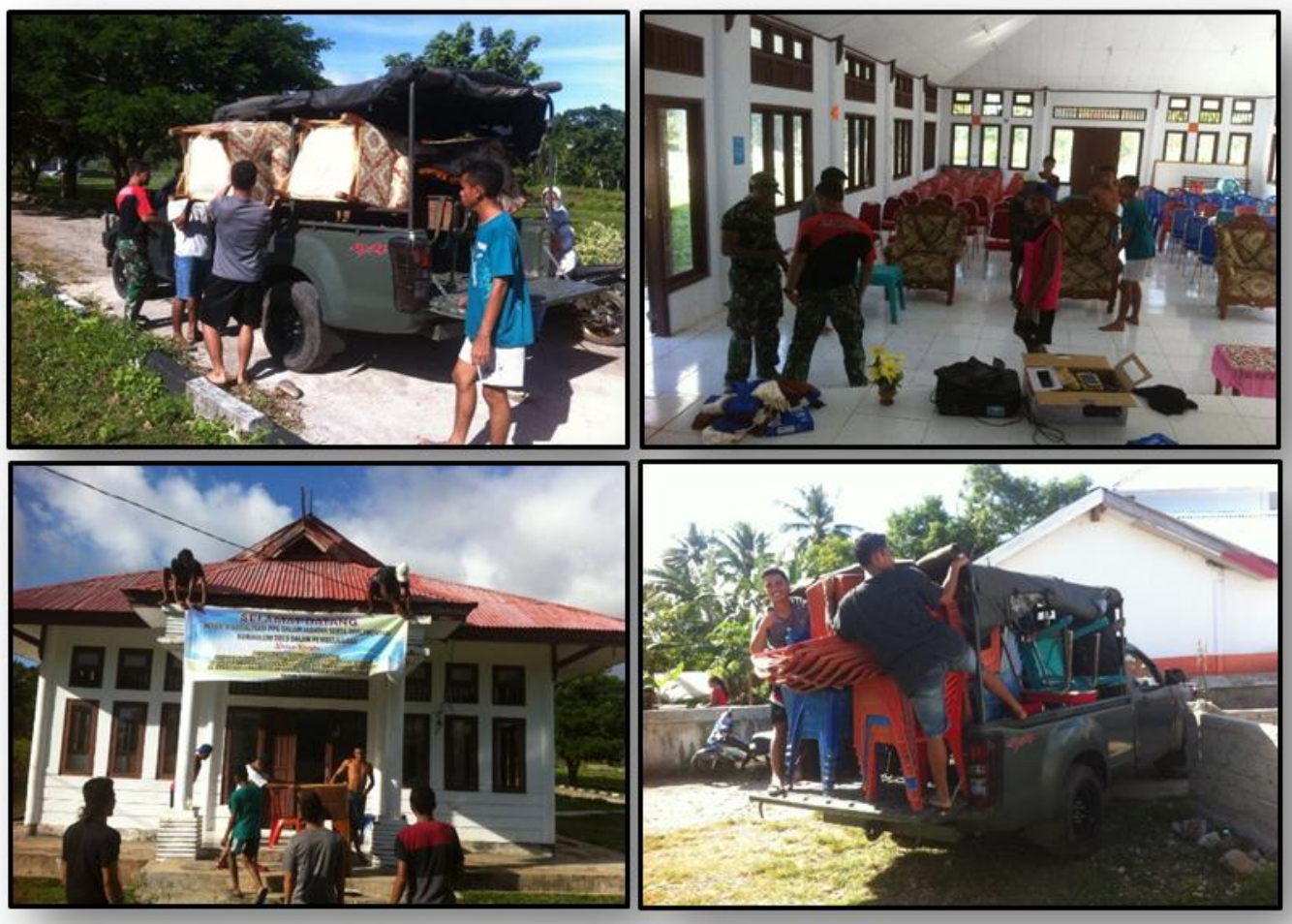

Gambar 3. Bekerja sama dengan Pihak Koramil 1507-03

Dalam berbagai kegiatan yang dilaksanakan apapun bentuknya, tidak pernah lepas dari hambatan. Maka dalam melaksankan pengabdian kepada masyarakat inipun terdapat hambatan yang harus dihadapi tim mulai dari persiapan s,d pelaksanaan dilapangan, antara lain;

1. Tidak ada koordinasi yang baik dari pihak koordinasi dan konvirmasi yang baik dari koordinator pendidikan di kecamatan Pulau-Pulau Babar, dengan pemerintah kecamatan untuk menghadapi kegiatan workshop, sehingga koordinasi dapat dilaksanakan oleh panitia baik dengan pimpinan dikecamatan, pimpinan desa saat tim pengabdian telah tiba di desa tepa yang merupakan lokasi pelaksanaan pengabdian. Bentuk koordinasi yang dilakukan dengan pemerintah kecamatan hanyalah penyampaian informasi kegiatan. Sehingga semua bentuk tugas dan tanggung jawab yang dikoordinasikan bersama dengan panitia pengabdian program studi samasekali tidak berjalan sesuai hasil pertemuan awal.

2. Oleh Karena tidak adanya koordinasi yang baik dari pihak coordinator pendidikan dengan pimpinan kecamatan dan juga pihak sekolah di kecamatan Pulau-Pulau Babar dengan kecamatan sekitar yaitu coordinator pendidikan kecamatan babar timur dan pulau wetang, maka turut berdampak hingga tidak sampainya informasi yang disampaikan kepada para guru di sekolah-sekolah baik di kecamatan PP.

Volume 1, Number 2, Juli 2020| 33 Implementation Workshop Curriculum 2013 In Learning In The District of Babar Islands - Southwestern Maluccas Regions

Mieke Souisa, Jacob Anaktototy, Wilhelmina Unmehopa, Mariana Hukubun, Emma Rumahlewang, Jonas Solissa, Johana Matitaputty 
GANDRUNG: Jurnal Pengabdian Kepada Masyarakat ISSN: 2721-6136 (Online)

Babar sendiri, bahkan di sekolah-sekolah kecamatan Babar Timur, dan kecamatan Pulau Wetang. Mengakibatkan banyak peserta yang tiba dilokasi kegiatan disiang hari karena terlambatnya informasi yang diperoleh, bahkan mengetahuinya pun secara pribadi.

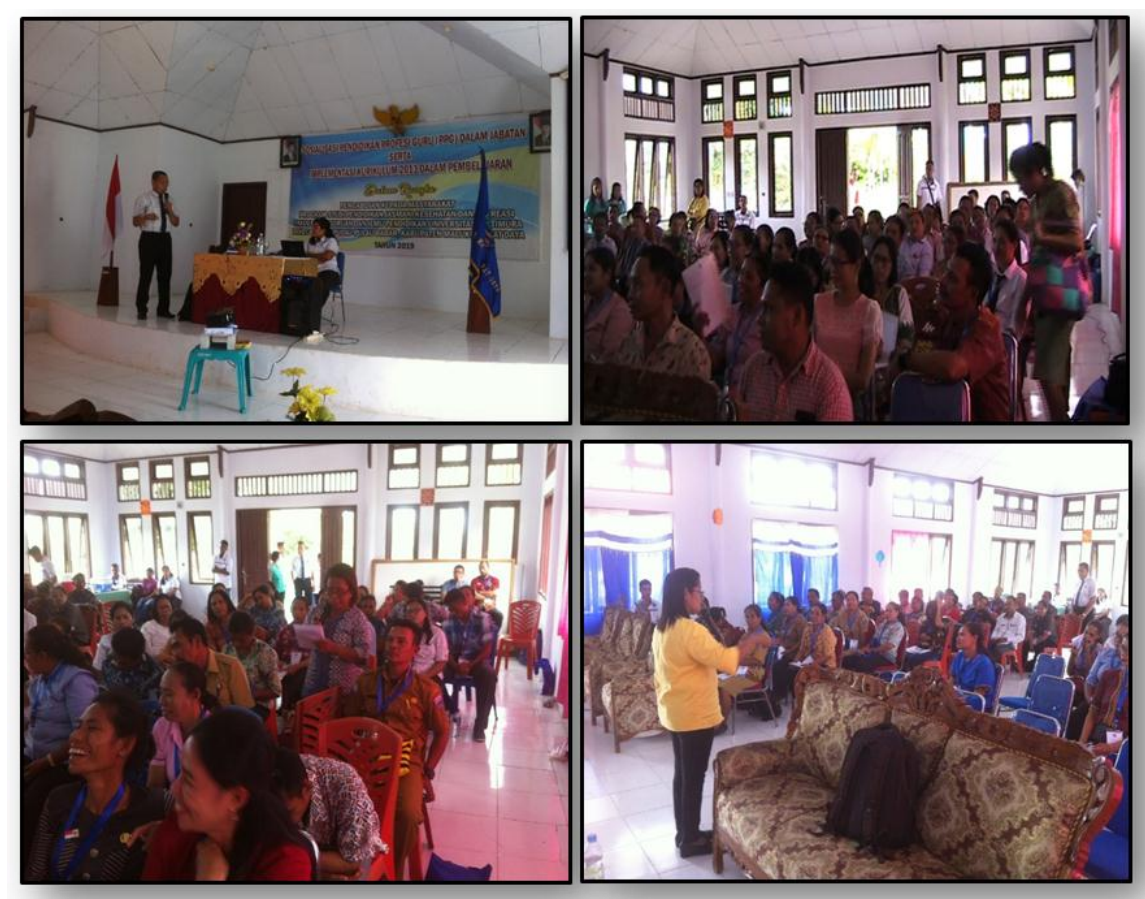

Gambar 4. Pelaksanaan Workshop Implementasi Kurikulum 2013

\section{Kesimpulan}

Kesimpulan yang dapat diangkat berdasarkan kegiatan pengabdian kepada masyarakat (PKM) yag dilaksanaka oleh tim dosen program studi pendidikan jasmani kesehatan dan rekreasi FKIP Unpatti di pulau terluar kecamatan Pulau-Pulau Babar, Kabupaten Maluku Barat Daya pada 11 dan 12 Juni 2019 adalah sebagai berikut:

1. Peserta memahami bagaimana merencanakan pembelajaran dengan kurikulum 2013.

2. Peserta memahami pendekatan yang umumnya digunakan dalam pembelajaran sesuai dengan cirikhas materi, baik pedekatan saintifik maupun tematik maupun metode pembelajaran yang sesuai dengan kurikulum 2013.

3. Berkembangnya pemahaman peserta tentang prosedur implementasi kurikulum 2013 dalam pembelajaran.

4. Peserta memahami bagaimana merencanakan evaluasi dalam kurikulum 2013.

5. Peserta memahami proses implementasi evaluasi yang telah direncanakan sebelumnya dengan

Volume 1, Number 2, Juli 2020 | 34 Implementation Workshop Curriculum 2013 In Learning In The District of Babar Islands - Southwestern Maluccas Regions

Mieke Souisa, Jacob Anaktototy, Wilhelmina Unmehopa, Mariana Hukubun, Emma Rumahlewang, Jonas Solissa, Johana Matitaputty 
GANDRUNG: Jurnal Pengabdian Kepada Masyarakat

ISSN: 2721-6136 (Online)

kurikulum 2013.

Berdasarkan pengalaman pengabdian di Kecamatan Pulau-Pulau. Babar Kabupaten Maluku Barat Daya, maka para peserta bahkan tim pengabdian sendiri berharap agar kegiatan-kegiatan seperti ini, sebagai LPTK jangan hanya dilakukan di pusat kota provinsi atau pada kabupaten/kecamatan disekitar (yang dekat), namun untuk meningkatkan kualitas tenaga pendidik dan juga mutu pembelajaran, maka harus melaksanakan kegiatan di kecamatan pulau terluar pula.

\section{Daftar Referensi}

T. G. Ratumanan. Imas Rosmiati. 2019. "Perencanaan Pembelajaran”. Jakarta: PT. Rajagrafindo Persada.

Jacob Anaktototy. Mieke Souisa. 2018. "The Analysis Of Ability Physical Education Teachers In Managing Learning At The Level Of A Junior High School In The Ambon City". The $3^{\text {rd Interational }}$ Semiar on Education 2018. Ambon: Pattimura Uinversity.

Mieke Souisa. Jacob Anaktototy. Dwi Anissa. "Kemampuan Guru Penjasor Menerapkan Kurikulum 2013 dalam Pembelajaran Pada Siswa Kelas X SMAN 3 Salahutu. Jurnal Kejaora. Jurnal Kesehatan Jasmani dan Olahraga. Volume 5 nomor 1. Edisi April 2020. ISSN Onlie: 2541-5042. ISSN Print: 2503-2796. Banyuwangi: Universitas PGRI Banyuwangi.

Mulyasa, E. 2013. "Menjadi Guru Profesional". Menciptakan Pembelajaran Kreatif dan Menyenangkan. Bandung: PT. Remaja Rosdakarya.

Mulyasa, H, E. 2014. "Pengembangan dan Implementasi Kurikulum 2013". Perubahan dan Pengembangan Kurikulum 2013 Merupakan Persoalan Penting dan Genting. Bandung: PT. Remaja Rosdakarya.

Mulyasa, Prof, Dr, H, E, M.Pd. 2017. "Pengembangan dan Implementasi Kurikulum 2013". Perubahan dan Pengembangan kurikulum 2013 merupakan persoalan penting dan genting. Bandung: PT. Remaja Rosdakarya.

Moleong, Lexi. J. 2012. "Metodologi Penelitian Dalam Olahraga”. Surabaya: Unesa University Press.

P,J,K,R. 2019. "Optimalisasi Kapasitas Guru Pendidikan Jasmani di Era 4.0”. Laporan Kegiatan Seminar Nasional Program Studi Pendidikan Jasmani Kesehatan dan Rekreasi. Ambon: FKIP Universitas Pattimura

Prastowo, Andi. 2011. "Metode Penelitian Kualitatif: dalam Perspektif Rancangan Penelitian". Cet. I. Jakarta: Departemen Pendidikan Nasional.

Prof. Dr. Jacob Anaktotoy, M.Pd, Mieke Souisa, M.Pd. 2018. "Analisis Kemampuan Guru Pendidikan Jasmani Dalam Mengelola Pembelajaran pada Jenjang Sekolah Menengah Perta di Kita Ambon". Laporan Penelitian. Ambon: FKIP Universitas Pattimura.

Prof. Dr. T.G. Ratumanan, M.pd, Imas Rosmiati, S.Pd., M.Pd. 2019. "Perencanaan Pembelajaran". Jakarta: PT. Rajagrafindo Persada.

Ratumanan, Gerson, Tanwey. Rosmiati Imas. 2014. "Perencanaan Pembelajaran". Surabaya: Unesa University Press.

Volume 1, Number 2, Juli 2020| 35

Implementation Workshop Curriculum 2013 In Learning In The District of Babar Islands - Southwestern Maluccas Regions

Mieke Souisa, Jacob Anaktototy, Wilhelmina Unmehopa, Mariana Hukubun, Emma Rumahlewang, Jonas Solissa, Johana Matitaputty 
GANDRUNG: Jurnal Pengabdian Kepada Masyarakat ISSN: 2721-6136 (Online)

Sugiyono. 2013. "Memahami Penelitian Kualitatif". Dilengkapi Contoh Proposal dan Laporan Penelitian. Jakarta: PT. RajaGrafindo Persada.

Sugiyono, 2011. "Metodologi Penelitian Kualitatif, Kuantitatif, dan R \& D". Dilengkapi Contoh Proposal dan Laporan Penelitian. Jakarta: PT. RajaGrafindo Persada. 